\title{
Transcatheter pulmonic valve implantation in adult patients with prior congenital heart surgery
}

\author{
Zachary A. Spigel ${ }^{1}$, Iki Adachi' ${ }^{2}$ Ziyad M. Binsalamah ${ }^{2}$, Dhaval Parekh ${ }^{3}$, Athar M. Qureshi ${ }^{3}$ \\ ${ }^{1}$ Department of Surgery, Allegheny Health Network, Pittsburgh, PA, USA; ${ }^{2}$ Department of Surgery, Baylor College of Medicine/Texas Children's \\ Hospital, Houston, TX, USA; ${ }^{3}$ The Lillie Frank Abercrombie Section of Cardiology, Department of Pediatrics, Texas Children's Hospital, Baylor \\ College of Medicine, Houston, TX, USA \\ Correspondence to: Dr. Athar M. Qureshi. The Lillie Frank Abercrombie Section of Cardiology, Texas Children's Hospital/Baylor College of Medicine, \\ 6651 Main Street, E 1920, Houston, TX 77030, USA. Email: axquresh@texaschildrens.org.
}

\begin{abstract}
Background: Transcatheter pulmonary valve replacement (TPVR) is now an established modality for pulmonary valve replacement in suitable candidates. We aim to describe our experience with TPVR in adults.

Methods: This is a descriptive study of all TPVR performed in adults with congenital heart disease at a single institution from 2010-2020. All adult patients (defined as 18 years old or older at TPVR) were included. Time-to-event outcomes were described using Kaplan-Meier estimates with 95\% confidence intervals (CIs).

Results: Out of a total of 200 patients that had undergone TPVR, 81 patients ( $57 \%$ male) met the inclusion criteria, with a median age and weight of 26 years (IQR 21-37) and $71.0 \mathrm{~kg}$ (IQR 54.6-89.0), respectively. In the cohort, $45(56 \%)$ patients had tetralogy of Fallot. While $53(65 \%)$ patients received a Melody valve, a Sapien valve (S3 in 20, XT in eight) was implanted in the rest. Pre-stenting was performed in 49 (52\%) patients. One patient died of severe heart failure a year following TPVR. One patient had a second TPVR performed 2.2 years following initial TPVR for severe pulmonary regurgitation. Valve survival at 2.2 years was 94\% (95\% CI: 87-100\%). Four patients developed endocarditis. Endocarditis-free survival was $89 \%$ (95\% CI: 80-100\%) at three years.

Conclusions: Our experience suggests favorable results of TPVR in adults with congenital heart disease. Additional research would be warranted with a focus on total valve longevity and patient reported outcomes, in order to improve the understanding of TPVR in this population and further refine this technology.
\end{abstract}

Keywords: Pulmonary valve; adult congenital heart disease; transcatheter valve replacement

Submitted Aug 16, 2021. Accepted for publication Sep 09, 2021.

doi: 10.21037/acs-2021-tviv-28

View this article at: https://dx.doi.org/10.21037/acs-2021-tviv-28

\section{Introduction}

Transcatheter pulmonary valve replacement (TPVR) has become an accepted modality of pulmonary valve replacement in suitable candidates. Large studies have demonstrated favorable hemodynamic profile in the midterm with both the Melody (Medtronic Inc., Minneapolis, MN, USA) and Edwards Sapien Transcatheter Heart Valve (Edwards Lifesciences, Irvine, CA, USA) (1-5). As the population of patients with congenital heart defects continues to age, understanding the role of TPVR in the interventional armamentarium becomes of increasing importance. Therefore, we aimed to describe our singlecenter experience with TPVR in adult patients.

\section{Methods}

\section{Patient population}

This study was approved by the Baylor College of Medicine Institutional Review Board with waiver of informed consent. The Texas Children's Hospital prospectively- 
maintained transcatheter pulmonary valve replacement database contains all patients undergoing TPVR from August 2010 through June 2020 including pre-procedure demographics, periprocedural data, and post-procedural outcomes. The database was queried for all adult patients (18 years or older) with congenital heart disease undergoing TPVR. Patients who underwent placement of a specifically designed TPV system for native outflow tracts e.g., the Harmony valve (Medtronic, Minneapolis, MN, USA) or Alterra Adaptive Prestent (Edwards Lifesciences, Irvine, CA, USA) were excluded from this study, as this technology has only become recently available.

\section{Interventions}

TPVR was performed using the standard technique. All procedures were performed with general anesthesia and biplane fluoroscopy/cineangiography. Heparin was administered to maintain activated clotting times of $>250$ seconds. In general, the femoral venous route was used for TPVR, however in some patients in whom the femoral veins were occluded, or who had extremely dilated right-sided structures (that made it challenging to deliver the valve from a femoral venous approach), the right internal jugular vein was used for TPVR delivery. All patients underwent coronary artery testing with balloon inflation in the right ventricular outflow tract (RVOT) to ensure the TPVR procedure would not result in coronary compression. TPVR was performed with the $22 \mathrm{~mm}$ Melody valve using 18, 20 or $22 \mathrm{~mm}$ ensemble delivery systems and with the Sapien valve using 23, 26 or $29 \mathrm{~mm}$ Sapien valves. A $65 \mathrm{~cm}$-long Gore Dryseal Sheath (W. L. Gore and Associates, Flagstaff, AZ, USA) (6) was used towards the latter part of our experience to deliver all Sapien valves, in order to decrease the risk of tricuspid valve injury from the delivery system. Rapid right ventricular pacing was performed in patients undergoing TPVR within a native RVOT. The site of TPVR delivery was closed using sutured mediated closure devices or a figure of eight stich. All patients were admitted for overnight observation.

\section{Study design and data collection}

The study was designed to be descriptive in nature in order to review the patient demographics, procedural techniques, and outcomes following TPVR in adult patients with congenital heart disease for the Texas Children's Hospital transcatheter pulmonary valve replacement database.
Echocardiographic and cardiac magnetic resonance imaging (MRI) data was collected, however the degree of valvular regurgitation by cardiac MRI was prioritized for data reporting in this study. Patient demographics were collected at the time of TPVR. The TPVR operative reports are prospectively reviewed for entry into the database. Outcome data are updated at each patient visit or following correspondence with the patient or primary cardiologist if the patient is not followed primarily at Texas Children's Hospital.

\section{Statistical analysis}

Continuous variables were assessed for normality graphically using histograms and QQ plots, and mathematically using the Shapiro-Wilk test for normality. Normally distributed variables were reported as mean ( \pm standard error) and skewed variables were reported as median (interquartile range). Categorical variables are presented as count and a corresponding percentage of known. Survival data are described using Kaplan-Meier estimates and graphed with corresponding $95 \%$ confidence intervals (CIs). Only one patient was known to be deceased, therefore the remaining patients were censored as being alive at the time of their last follow-up. Valve survival was defined as freedom from valve explantation, valve-in-valve TPVR, or patient death. The cumulative incidence of endocarditis was calculated accounting for death prior to the development of endocarditis as a competing risk. As the study was designed to be descriptive in nature, no formal statistical testing was performed. All statistical analysis was performed with $\mathrm{R}$ version 4.1.0 (R Foundation for Statistical Computing, Vienna, Austria).

\section{Results}

\section{Pre-procedural demographics}

A total of 200 consecutive TPVR procedures were reviewed, of which, $81(40.5 \%)$ were performed on patients older than 18 years. The majority of patients were male (46/81, 57\%) and the median age was 26 years (IQR 21-37) with median weight $71.0 \mathrm{~kg}$ (IQR 54.6-89.0). In the cohort, 45 (56\%) patients had tetralogy of Fallot, ten (12\%) patients had a prior Ross procedure, seven (9\%) had congenital pulmonary stenosis, five $(6 \%)$ had double outlet right ventricle with transposition of the great arteries, four (5\%) had pulmonary atresia $(\mathrm{PA})$ with intact ventricular septum, four (5\%) PA 
with ventricular septal defect (PA/VSD), four (5\%) with truncus arteriosus, and two (2\%) had other defects. The majority of TPVR procedures were performed into RVOT consisting of homografts $(31 / 81,38 \%)$, bioprosthetic valves (23/81, 28\%), or native RVOT $(16 / 81,20 \%)$. For patients with conduits, the median time since last conduit placement was 15 years (IQR 10-21) with 7/81 (9\%) patients having previously placed RVOT conduit stents. Prosthetic valves had been placed in heterotopic positions in four $(5 \%)$ patients, including two in the tricuspid position, one aortic position, and one mitral position. A permanent pacemaker had been established in eight $(10 \%)$ patients, including five $(6 \%)$ transvenous and three (4\%) epicardial. Three patients (4\%) had a prior history of endocarditis.

Prior to TPVR, two (2\%) patients had severe tricuspid regurgitation by echocardiogram or MRI, 22 (27\%) had moderate regurgitation, and $34(42 \%)$ had mild regurgitation. The mean RVOT gradient was $28 \mathrm{mmHg}$ (IQR 11-38 $\mathrm{mmHg}$ ) by echocardiogram with a maximum RVOT gradient of $44 \mathrm{mmHg}$ (IQR 25-66 mmHg). Preoperative evaluation by echocardiogram or MRI demonstrated severe pulmonary regurgitation in 44 (54\%) patients, moderate regurgitation in $22(27 \%)$ patients, and mild regurgitation in nine $(11 \%)$ patients. Table 1 reviews all pre-procedural demographics for the 81 adult patients undergoing TPVR.

\section{Transcatheter pulmonary valve replacement}

A Melody valve was implanted in $53(65 \%)$ patients with a Sapien valve implanted in 28 (35\%) patients (S3 in 20, XT in eight). Pre-stenting was performed in 49 (52\%) patients, including two stents in nine $(11 \%)$ patients and three stents in two $(2 \%)$ patients. Post-dilatation was performed in $55(68 \%)$ patients. Concomitant procedures were performed in $13(16 \%)$ patients and six (7\%) patients experienced periprocedural complications. The median RVOT gradient following TPVR was seven (IQR 4-10) mmHg. Procedural details are presented in Table 2. We placed a TPV in $23(28 \%)$ patients with an existing bioprosthetic pulmonary valve (valve-in-valve procedure) and in two patients in this series, frame fracture of the bioprosthetic valve was performed with high pressure balloons, to allow for a larger TPV orifice.

\section{Outcomes}

Median follow-up was 1.1 years (IQR 0.1-3.3 years). The most recent mean RVOT gradient was a median $14 \mathrm{mmHg}$ (IQR 9-18 $\mathrm{mmHg}$ ) with median maximum RVOT gradient $19 \mathrm{mmHg}$ (IQR 15-27 mmHg). At most recent echocardiogram or MRI, pulmonary regurgitation was severe in one $(1 \%)$ patient, moderate in six $(7 \%)$ patients, mild in $21(26 \%)$ patients, and trivial-to-none in $53(66 \%)$ patients. One patient died 1.04 years following TPVR from severe heart failure. Overall survival at the median followup time of 1.1 years was $98 \%$ (95\% CI: $93-100 \%$, Figure 1). One patient had a second TPVR performed 2.18 years following initial TPVR for severe pulmonary regurgitation. Valve survival after 2.2 years was $94 \%$ (95\% CI: $87-100 \%$, Figure 2). Patient outcomes are summarized in Table 3.

\section{Endocarditis}

Patients were followed for a total 167 valve-years of follow-up. Four patients developed endocarditis at 99, 712, 839, and 2,442 days following TPVR, respectively. Endocarditis occurred at an incidence rate of 2.4 cases per 100 valve-years of follow-up. The cumulative incidence of endocarditis was 2\% (95\% CI: 0-6\%, Figure 3) at one year and $8 \%$ (95\% CI: $0-16 \%)$ at three years. Blood cultures were positive in three (75\%) patients and included Staph aureus, Strep mitis, and Rothia dentocariosa. Only one (25\%) patient had echocardiographic evidence of TPVR involvement. A summary of the patients that developed endocarditis is presented in Table 4. All patients were treated with six weeks of antibiotics and none required valve explantation.

\section{Discussion}

\section{Summary}

This series demonstrates favorable results with TPVR in the adult congenital heart disease population. A limited number of patients have experienced major complications, including endocarditis and severe pulmonary regurgitation, and only one patient died during follow-up as a result of heart failure unrelated to the TPVR. During follow-up the development of worse than mild pulmonary regurgitation or elevated valve gradients were rare events.

\section{Relation to prior studies}

Compared to other series, this series had a similar proportion of patients with tetralogy of Fallot as the underlying 


\begin{tabular}{|c|c|}
\hline Demographics & All $(n=81)$ \\
\hline Age (years) & $26[21-37]$ \\
\hline Weight (kg) & $71.0(54.6-89.0)$ \\
\hline Male sex & $46(57 \%)$ \\
\hline \multicolumn{2}{|l|}{ Congenital defect } \\
\hline Tetralogy of Fallot & $45(56 \%)$ \\
\hline Ross & $10(12 \%)$ \\
\hline Pulmonary stenosis & 7 (9\%) \\
\hline $\mathrm{DORV}+\mathrm{TGA}$ & $5(6 \%)$ \\
\hline PAIVS & $4(5 \%)$ \\
\hline PAVSD & $4(5 \%)$ \\
\hline Truncus arteriosus & $4(5 \%)$ \\
\hline Other & $2(2 \%)$ \\
\hline \multicolumn{2}{|c|}{ RVOT conduit/valve type } \\
\hline Homograft & $31(38 \%)$ \\
\hline Bioprosthetic valve & $23(28 \%)$ \\
\hline Native RVOT/valve & $16(20 \%)$ \\
\hline Valved conduit & $2(2 \%)$ \\
\hline Contegra & $2(2 \%)$ \\
\hline Other & $5(6 \%)$ \\
\hline Unknown & $1(1 \%)$ \\
\hline \multicolumn{2}{|l|}{ Original conduit size } \\
\hline $13 \mathrm{~mm}$ & $1(1 \%)$ \\
\hline $15 \mathrm{~mm}$ & $1(1 \%)$ \\
\hline $16 \mathrm{~mm}$ & $2(2 \%)$ \\
\hline $17 \mathrm{~mm}$ & $1(1 \%)$ \\
\hline $18 \mathrm{~mm}$ & $5(6 \%)$ \\
\hline $19 \mathrm{~mm}$ & $1(1 \%)$ \\
\hline $20 \mathrm{~mm}$ & $2(2 \%)$ \\
\hline $21 \mathrm{~mm}$ & $1(1 \%)$ \\
\hline $22 \mathrm{~mm}$ & $8(10 \%)$ \\
\hline $23 \mathrm{~mm}$ & $13(16 \%)$ \\
\hline $24 \mathrm{~mm}$ & $4(5 \%)$ \\
\hline $25 \mathrm{~mm}$ & $13(16 \%)$ \\
\hline $26 \mathrm{~mm}$ & $2(2 \%)$ \\
\hline $27 \mathrm{~mm}$ & $6(7 \%)$ \\
\hline
\end{tabular}

\begin{tabular}{ll} 
Table 1 (continued) & \\
\hline Demographics & All $(\mathrm{n}=81)$ \\
\hline Time since last conduit placement in years & $15[10-21]$ \\
\hline Existing RVOT conduit stents present & $7(9 \%)$ \\
Other prosthetic valves & \\
Tricuspid & $2(2 \%)$ \\
Aortic & $1(1 \%)$ \\
Mitral & $1(1 \%)$ \\
None & $77(95 \%)$
\end{tabular}

Existing permanent

$\begin{array}{ll}\text { Pacemaker } & 73(90 \%) \\ \text { None } & 5(6 \%) \\ \text { Transvenous } & 3(4 \%) \\ \text { Epicardial } & \end{array}$

\begin{tabular}{ll} 
Prior history of endocarditis $3(4 \%)$ \\
\hline Tricuspid regurgitation severity (Echo/MRI)
\end{tabular}

Tricuspid regurgitation severity (Echo/MRI)

$\begin{array}{ll}\text { None } & 3(4 \%) \\ \text { Trivial } & 17(21 \%) \\ \text { Mild } & 34(42 \%) \\ \text { Moderate } & 22(27 \%) \\ \text { Severe } & 2(2 \%)\end{array}$

\begin{tabular}{|ll}
\hline Echo RVOT max gradient pre-op & $44[25-66]$ \\
\hline Echo RVOT mean gradient pre-op & $28[11-38]$ \\
\hline Pre-implant RV systolic pressure & $52[43-70]$ \\
\hline Pre-implant systolic PA pressure & $28.5 \pm 7.4$ \\
\hline Pre-implant mean PA pressure & $18.1 \pm 5.1$ \\
\hline RVOT peak gradient & $24[9-40]$ \\
\hline Pre-implant aortic systolic pressure & $90[83-100]$ \\
\hline Narrowest RVOT diameter & $16.5(4.7)$ \\
\hline Pulmonary regurgitation pre-op (Echo/MRI) \\
\hline None & $3(4 \%)$ \\
\hline Trivial & $2(2 \%)$ \\
\hline Mild & $9(11 \%)$ \\
\hline Moderate & $22(27 \%)$ \\
\hline Severe & $44(54 \%)$ \\
\hline
\end{tabular}

Data are presented as $\mathrm{N}(\%)$, median [interquartile range] or mean \pm standard deviation. DORV, double-outlet right ventricle; TGA, transposition of the great arteries; PAIVS, pulmonary atresia with intact ventricular septum; PAVSD, pulmonary atresia with ventricular septal defect; RVOT, right ventricular outflow tract; mm, millimeter; Echo, echocardiogram; MRI, magnetic resonance imaging. 


\begin{tabular}{|c|c|}
\hline Variable & Value \\
\hline \multicolumn{2}{|l|}{ TPV type } \\
\hline Melody & $53(65 \%)$ \\
\hline Sapien & $28(35 \%)$ \\
\hline \multicolumn{2}{|l|}{ Valve size } \\
\hline $18 \mathrm{~mm}$ & $7(9 \%)$ \\
\hline $20 \mathrm{~mm}$ & $2(2 \%)$ \\
\hline $22 \mathrm{~mm}$ & $42(52 \%)$ \\
\hline $23 \mathrm{~mm}$ & $4(5 \%)$ \\
\hline $24 \mathrm{~mm}$ & $1(1 \%)$ \\
\hline $25 \mathrm{~mm}$ & $1(1 \%)$ \\
\hline $26 \mathrm{~mm}$ & $11(14 \%)$ \\
\hline $29 \mathrm{~mm}$ & $13(16 \%)$ \\
\hline \multicolumn{2}{|l|}{ Number of pre-stents performed } \\
\hline None & $39(48 \%)$ \\
\hline One & $31(38 \%)$ \\
\hline Two & $9(11 \%)$ \\
\hline Three & $2(2 \%)$ \\
\hline Post-dilatation performed & $26(32 \%)$ \\
\hline \multicolumn{2}{|l|}{ Concomitant procedures Performed } \\
\hline Pulmonary valvuloplasty & $4(5 \%)$ \\
\hline Left PA angioplasty & $3(4 \%)$ \\
\hline Right PA angioplasty & $2(2 \%)$ \\
\hline Tricuspid valve implant & $2(2 \%)$ \\
\hline Aortopulmonary collateral closure & $1(1 \%)$ \\
\hline Impella placement & $1(1 \%)$ \\
\hline \multicolumn{2}{|l|}{ Complications } \\
\hline Cardiac arrest & $2(2 \%)$ \\
\hline Bronchial hemorrhage & $1(1 \%)$ \\
\hline Atrial flutter & $1(1 \%)$ \\
\hline RFA pseudoaneurysm & $1(1 \%)$ \\
\hline Valve malposition & $1(1 \%)$ \\
\hline Post-valve RV systolic pressure & $39 \pm 8.9$ \\
\hline Post-valve systolic PA pressure & 32 [27-36] \\
\hline
\end{tabular}

\begin{tabular}{ll} 
Table 2 (continued) & \\
\hline Variable & Value \\
\hline Post-valve mean PA pressure & $21[17-25]$ \\
\hline Post-valve RVOT gradient peak & $7[4-10]$ \\
\hline Post-valve aortic pressure & $101 \pm 14.3$ \\
\hline
\end{tabular}

Data are presented as $\mathrm{N}(\%)$, median [interquartile range], or mean \pm standard deviation. TPV, transcatheter pulmonary valve; RFA, right femoral artery; RV, right ventricle; PA, pulmonary artery, RVOT, right ventricular outflow tract.

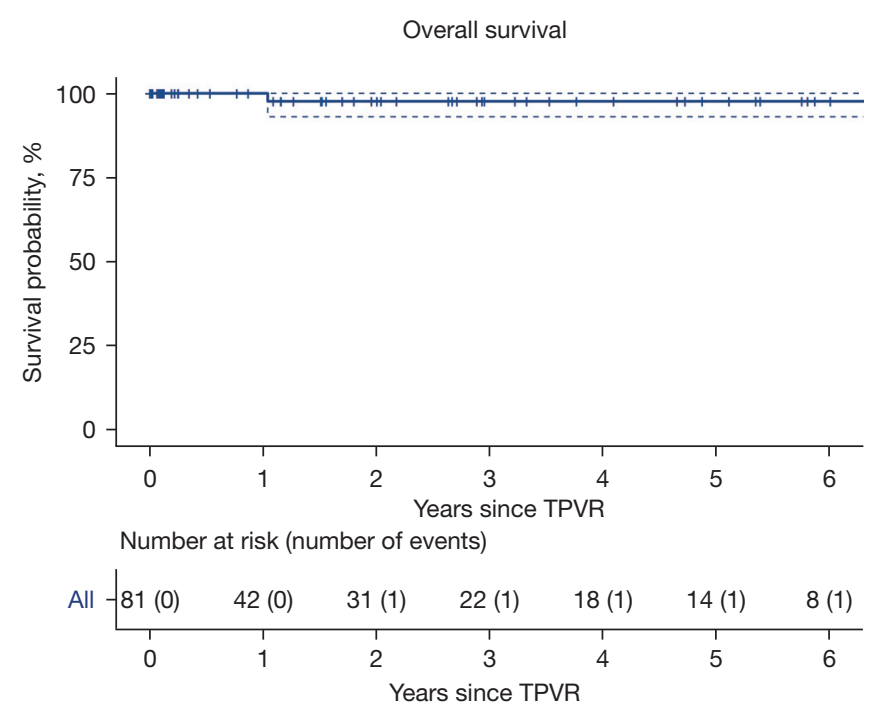

Figure 1 Overall survival following transcatheter pulmonary valve replacement. Dotted lines represent $95 \%$ confidence intervals. Survival was $100 \%$ (95\% CI: $100-100 \%$ ) at one year and $98 \%$ (95\% CI: 93-100\%) at two and three years. TPVR, transcatheter pulmonary valve replacement.

congenital defect (1-5). These studies report $0-4 \%$ of patients requiring a reintervention during follow-up, a range that includes our reported $1 \%$. Compared to a report of surgical implantation of Epic Supra valves (7) the TPVR patients had similar rates of freedom from valve replacement (100\% compared to $94 \%$ at three years). Our rate of 2.4 cases of endocarditis per 100 valve-years follow-up is similar to a recently published multicenter study, which reported 2.2 cases per 100 valve-years of follow-up (8). In our study, all patients who had endocarditis had undergone TPVR with a Melody valve, however, endocarditis has been observed 


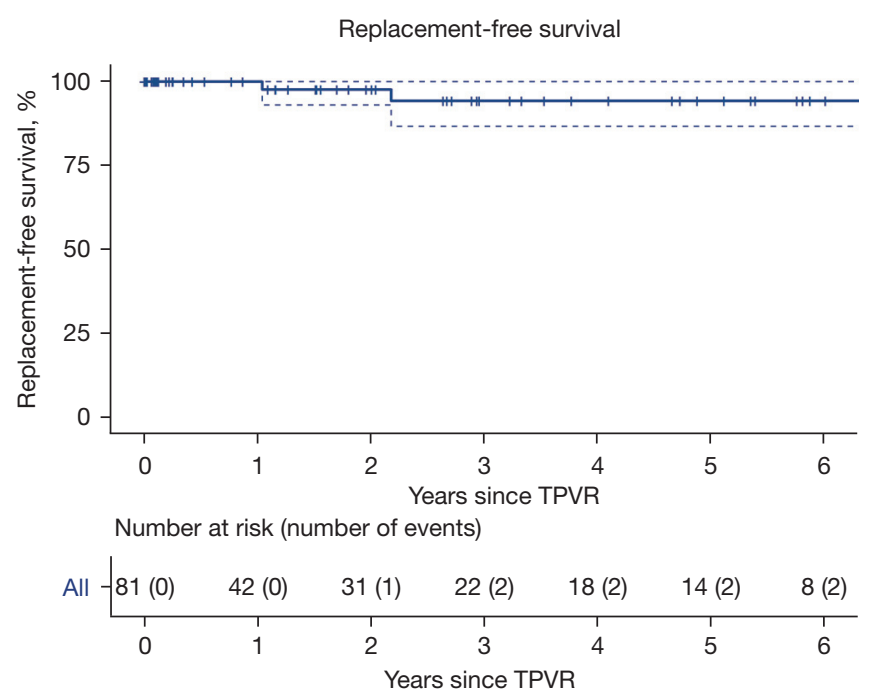

Figure 2 Valve survival following transcatheter pulmonary valve replacement. Dotted lines represent $95 \%$ confidence intervals. Freedom from valve replacement or death was 100\% (95\% CI: $100-100 \%)$ at one year, 98\% (95\% CI: 93-100\%) at two years, and 94\% (95\% CI: 87-100\%) at three years. TPVR, transcatheter pulmonary valve replacement.

with both Melody and Sapien valves (8). In addition, factors other than the valve type should be considered in the overall risk assessment for development of possible endocarditis for these patients. A study of all patients undergoing TPVR identified older age was associated with improved freedom from valve replacement and a freedom from endocarditis $>90 \%$ (9) and another study found age of $<12$ years of age and residual gradients of $>15 \mathrm{mmHg}$ to be risk factors for development of endocarditis (10). In most cases, endocarditis can be treated with antibiotic therapy with or without surgical replacement of the TPVR, and in some instances (e.g., fungal endocarditis), lifelong oral therapy may be needed (11).

In this series, we placed a TPV in $23(28 \%)$ of patients with an existing bioprosthetic pulmonary valve (valve-invalve procedure). This has been found to be effective if the internal diameter of the bioprosthetic valve is sufficient (2). In addition, frame fracture of the bioprosthetic valve was performed with high pressure balloons in this particular cohort in two patients. If this can be performed (depending on the bioprosthetic valve type), this allows for a larger effective orifice of the TPV (12). We administer lifelong

\begin{tabular}{ll}
\hline Table 3 Outcomes & \\
\hline Variable & Values \\
\hline Follow-up duration (years) & $1.1[0.1-3.3]$ \\
\hline Most recent echo max RVOT gradient & $19[15-27]$ \\
\hline Most recent echo mean RVOT gradient & $14[9-18]$ \\
\hline Most recent echo or MRI PR severity & \\
\hline None & $29(36 \%)$ \\
\hline Trivial & $24(30 \%)$ \\
\hline Mild & $21(26 \%)$ \\
\hline Moderate & $6(7 \%)$ \\
\hline Severe & $1(1 \%)$ \\
\hline Endocarditis diagnosed & $4(5 \%)$ \\
\hline Any RVOT reintervention & $1(1 \%)$ \\
\hline Death & $1(1 \%)$ \\
\hline
\end{tabular}

Data are presented as $\mathrm{N}$ (\%) or median [interquartile range]. Echo, echocardiogram; RVOT, right ventricular outflow tract; $\mathrm{MRI}$, magnetic resonance imaging; PR, pulmonary regurgitation.

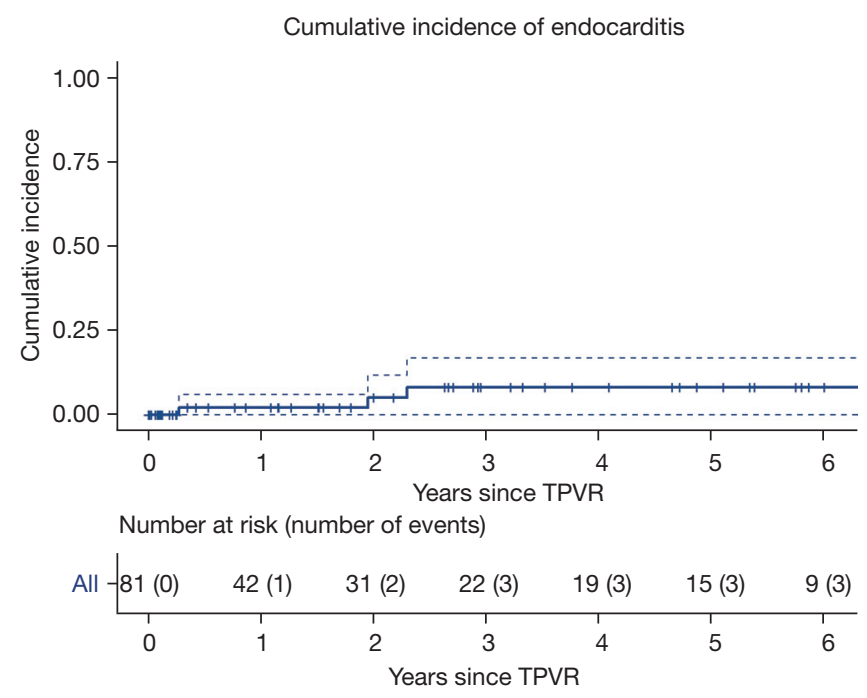

Figure 3 Cumulative incidence of endocarditis following transcatheter pulmonary valve replacement accounting for death as a competing risk. Dotted lines represent $95 \%$ confidence intervals. The cumulative incidence of endocarditis was 2\% (95\% CI: 0-6\%) at one year, $5 \%$ (95\% CI: $0-12 \%$ ) at two years, and $8 \%(95 \%$ CI: $0-16 \%)$ at three years. TPVR, transcatheter pulmonary valve replacement. 


\begin{tabular}{|c|c|c|c|c|c|c|c|c|c|c|}
\hline 2 & 25 & M & TOF & Perimount & - & Melody & 839 & + & $\begin{array}{l}\text { Rothia } \\
\text { dentocariosa }\end{array}$ & - \\
\hline 4 & 23 & M & Ross & Non-valved Goretx & + & Melody & 99 & + & Staph aureus & - \\
\hline
\end{tabular}

aspirin to patients after TPVR and in some patients with bioprosthetic valves (surgical or transcatheter) we have used anticoagulation for three to six months (13).

\section{Implications and surgical planning for future TPVR}

Despite these limitations, the presented series can be used to support the use of TPVR in the adult congenital heart disease population and represents an alternative to a redo sternotomy for the indication of pulmonary valve replacement. While the demand for pulmonary valve replacement is smaller in adults with acquired heart disease, it would be reasonable to expect similar results following TPVR in the acquired population, if not improved, compared to the population of adults with congenital heart disease.

More and more patients nowadays are demanding minimally invasive procedures, particularly patients with multiple comorbidities or patients with prior multiple surgeries. For that reason and in anticipation for future TPVR, surgeons nowadays try their best to implant the biggest right ventricle to pulmonary artery conduits or surgical pulmonary valves possible at the time of surgery; whether in initial or subsequent surgeries; to give their patients the chance to have TPVR in the future as an alternative to redo-surgeries to upsize their conduits. Other special circumstances must also be considered. In patients who have undergone a Ross operation, iatrogenic aortopulmonary fistulas may occur after the TPVR procedure $(14,15)$ and future surgeries on the RVOT may also require aortic root re-replacement. Future research should also be undertaken to mitigate such scenarios.

\section{Limitations}

This study is limited by the relatively short follow-up among the patient cohort and it is imperative to follow these patients closely over time to determine the true longevity of TPVR in this specific patient population. Additionally, these patients represent a carefully selected population from a single center and may not represent generalizable results if applied to the total adult congenital heart disease population. Unfortunately, due to sample size and limited number of complications, patient and operative factors could not be evaluated for association with the development of endocarditis or valve replacement. Finally, not all patients are followed by cardiologists within our institution, therefore, the most recent follow-ups for some patients are dependent on updates provided by the patient's local cardiologist.

\section{Future directions}

Additional research should focus on comparison of transcatheter and surgical techniques for pulmonary valve replacement, although these studies may be limited by the differing indications for performing surgical and transcatheter pulmonary valve replacements. Efforts should be taken to understand the natural history of valve degeneration and functional outcomes in-vivo following transcatheter deployment. Finally, understanding patientcentered outcomes, such as return to normal activities, freedom from hospitalization, and freedom from additional procedures would assist policy makers and patients in appreciating the role of TPVR in the armamentarium of managing the adult congenital heart disease population. 
TPVR procedures in adults, who require multiple cardiac surgical and interventional procedures over their lifetime, represents a vital area of collaboration between cardiac surgeons and interventional cardiologists.

\section{Conclusions}

Many adults who have undergone prior congenital heart surgery can undergo TPVR with favorable results. Future research in this population is needed with a focus on total valve longevity and patient reported outcomes. Improvement in our understanding of the interplay between TPVR and surgical PVR in this population will help further refine this technology.

\section{Acknowledgments}

Funding: None.

\section{Footnote}

Conflicts of Interest: Dr. AMQ has consulting relationships with Medtronic, Edwards Lifesciences, W.L. Gore \& Associates, and Abiomed Inc. The other authors have no conflicts of interest to declare.

Open Access Statement: This is an Open Access article distributed in accordance with the Creative Commons Attribution-NonCommercial-NoDerivs 4.0 International License (CC BY-NC-ND 4.0), which permits the noncommercial replication and distribution of the article with the strict proviso that no changes or edits are made and the original work is properly cited (including links to both the formal publication through the relevant DOI and the license). See: https://creativecommons.org/licenses/by-nc-nd/4.0/.

\section{References}

1. Wilson WM, Benson LN, Osten MD, et al. Transcatheter Pulmonary Valve Replacement With the Edwards Sapien System: The Toronto Experience. JACC Cardiovasc Interv 2015;8:1819-27.

2. Cabalka AK, Asnes JD, Balzer DT, et al. Transcatheter pulmonary valve replacement using the melody valve for treatment of dysfunctional surgical bioprostheses: A multicenter study. J Thorac Cardiovasc Surg 2018;155:1712-1724.e1.
3. Cheatham JP, Hellenbrand WE, Zahn EM, et al. Clinical and hemodynamic outcomes up to 7 years after transcatheter pulmonary valve replacement in the US melody valve investigational device exemption trial. Circulation 2015;131:1960-70.

4. Shahanavaz S, Zahn EM, Levi DS, et al. Transcatheter Pulmonary Valve Replacement With the Sapien Prosthesis. J Am Coll Cardiol 2020;76:2847-58.

5. Kreutzer J, Armstrong AK, Rome JJ, et al. Comparison of the investigational device exemption and post-approval trials of the Melody transcatheter pulmonary valve. Catheter Cardiovasc Interv 2021;98:E262-74.

6. Kenny D, Morgan GJ, Murphy M, et al. Use of $65 \mathrm{~cm}$ large caliber Dryseal sheaths to facilitate delivery of the Edwards SAPIEN valve to dysfunctional right ventricular outflow tracts. Catheter Cardiovasc Interv 2019;94:409-13.

7. Spigel ZA, Zhu H, Qureshi AM, et al. Durability of the St. Jude Epic Supra Bioprosthetic Valve in the Pulmonary Position. Semin Thorac Cardiovasc Surg 2021;33:184-91.

8. McElhinney DB, Zhang Y, Aboulhosn JA, et al. Multicenter Study of Endocarditis After Transcatheter Pulmonary Valve Replacement. J Am Coll Cardiol 2021;78:575-89.

9. Armstrong AK, Berger F, Jones TK, et al. Association between patient age at implant and outcomes after transcatheter pulmonary valve replacement in the multicenter Melody valve trials. Catheter Cardiovasc Interv 2019;94:607-17.

10. McElhinney DB, Sondergaard L, Armstrong AK, et al. Endocarditis After Transcatheter Pulmonary Valve Replacement. J Am Coll Cardiol 2018;72:2717-28.

11. Baddour LM, Wilson WR, Bayer AS, et al. Infective Endocarditis in Adults: Diagnosis, Antimicrobial Therapy, and Management of Complications: A Scientific Statement for Healthcare Professionals From the American Heart Association. Circulation 2015;132:1435-86.

12. Shahanavaz S, Asnes JD, Grohmann J, et al. Intentional Fracture of Bioprosthetic Valve Frames in Patients Undergoing Valve-in-Valve Transcatheter Pulmonary Valve Replacement. Circ Cardiovasc Interv 2018;11:e006453.

13. Egbe AC, Connolly HM, Miranda WR, et al. Outcomes of Bioprosthetic Valves in the Pulmonary Position in Adults With Congenital Heart Disease. Ann Thorac Surg 2019;108:1410-5.

14. Torres A, Sanders SP, Vincent JA, et al. Iatrogenic aortopulmonary communications after transcatheter 
interventions on the right ventricular outflow tract or pulmonary artery: Pathophysiologic, diagnostic, and management considerations. Catheter Cardiovasc Interv 2015;86:438-52.

15. Broda CR, Mulukutla V, Bansal M, et al. Use of Intracardiac
Echocardiography in the Evaluation and Management of Iatrogenic Aortopulmonary Communication After Percutaneous Intervention in Postoperative Patients With Congenital Heart Disease. World J Pediatr Congenit Heart Surg 2020;11:338-42.

Cite this article as: Spigel ZA, Adachi I, Binsalamah ZM, Parekh D, Qureshi AM. Transcatheter pulmonic valve implantation in adult patients with prior congenital heart surgery. Ann Cardiothorac Surg 2021;10(5):658-666. doi: 10.21037/acs-2021-tviv-28 